\title{
Cosmetic Procedures in the Treatment of Alopecia
}

\author{
Selda Pelin Kartal, Cemile Altunel and \\ Bilgen Gencler
}

Additional information is available at the end of the chapter

http://dx.doi.org/10.5772/66747

\begin{abstract}
Alopecia has a significant negative impact on the quality of life. Unfortunately, there is no satisfactory cure for most types of alopecia. Alopecia is divided into cicatricial and noncicatricial types. Androgenetic alopecia, alopecia areata, and telogen effluvium are common forms of noncicatricial alopecias. In order to treat or improve the appearance, various procedures that are being applied for different types of alopecia including mesotherapy, microneedling, platelet-rich plasma, low-level light therapy, and stem-cell therapy with variable outcomes are reviewed in this chapter.
\end{abstract}

Keywords: alopecia, hair loss, mesotherapy, microneedling, platelet-rich plasma, lowlevel light therapy, stem-cell therapy

\section{Introduction}

Alopecia (hair loss) is a common problem in dermatology setting and it has a significant negative impact on the quality of life. Therefore, most patients seek for treatment in order to improve their appearance although there is no satisfactory cure for most types of alopecia. Alopecia is divided into cicatricial and noncicatricial types. Androgenetic alopecia (AGA), alopecia areata (AA), and telogen effluvium are common forms of noncicatricial alopecias. Telogen effluvium is the diffuse hair shedding caused by physiological, hormonal metabolic stress, or by drugs. AGA is caused by the effect of dihydrotestosterone (DHT) on hair follicles leading to their miniaturization. It is seen in different appearances in males and females. In males, AGA presents as hairline recession and vertex balding. Unlike in men, female pattern hair loss (FPHL) is characterized by diffuse hair thinning over the crown with retention of the frontal hairline. AA is caused by autoimmune destruction of hair follicles involving cell-based and humoral immunity [1]. 
Various cosmetic procedures are being applied for different types of alopecia including mesotherapy, microneedling, platelet-rich plasma (PRP), low-level light therapy, and stem-cell therapy with variable outcomes $[2,3]$.

In this chapter, the above-mentioned cosmetic treatments for alopecia are briefly described.

\section{Mesotherapy in alopecia treatment}

\subsection{Introduction}

Mesotherapy is a noninvasive technique in which active substances are delivered just below the epidermis via superficial microinjections. Various substances including vitamins, medications, plant extracts, and other bioactive compounds including vasodilators, finasteride, and minoxidil can be injected intradermally or subcutaneously to reach the target tissues in mesotherapy [4].

There is evidence regarding the clinical efficacy of mesotherapy in the treatment of thermal burns, local pain, local fat contouring, and skin aging [5-8].

Although evidence-based studies regarding the efficacy of mesotherapy in different types of alopecia are lacking, in recent years, mesotherapy is increasingly being used in the treatment of telogen effluvium, androgenetic alopecia, and alopecia areata [9-11].

\subsection{Method}

Before starting hair mesotherapy, informed consent should be taken from the patient. After cleaning the scalp with antiseptic solution, the substances can be given by intraepidermal, papular, nappage, or point-by-point technique. In hair mesotherapy usually 4-6 mm, 27-32 G special mesotherapy needles are applied a depth of 4-6 mm about 1-2 $\mathrm{cm}$ apart. Although superficial intradermal technique is most commonly used, nappage technique can also be used manually or by mesotherapy gun. Hair mesotherapy can also be applied by using mesoroller device [9-11]. Each session lasts for 10-30 $\mathrm{min}$ [9]. There is no standardized protocol for the frequency of sessions and it depends on the decision of the applier and the indication it is done for. Hair mesotherapy is commonly applied at intervals of $1-4$ weeks [10,11]. Frequently accepted schedule is once a week for the initial weeks then with longer intervals and maintenance treatment in every 2-3 months [12]. Some clinics prefer to apply mesotherapy once in two weeks for at least 10 sessions and then once a month for 5 months [10].

\subsection{Mechanism of action}

Although the exact mechanism how the mesotherapy works is not known, several theories have been speculated. According to Pistor, skin may be a point for stimulation which is triggered by mesotherapy that sends inhibitory signals reaching to the lateral medullary center of the spinal cord. These inhibitory signals have been suggested to be either produced by the needling itself or the pharmacologic substances given during mesotherapy. The negative signals are suggested to restore the pathologic mechanisms causing alopecia [13]. The 
target tissue of hair mesotherapy is mostly the dermis including the circulatory, neuronal, and immune component. Also, epidermis and subcutaneous tissue are affected by the procedure of diffusion of substances. According to mesodermic theory, mesotherapy acts on the tissues derived from mesoderm including capillary and venous spaces, neuronal components, and immune cells of the skin $[13,14]$. Another explanation is the third circulation theory that, after blood (first) and the lymphatic (second) circulation, interstitial compartment between skin cells are considered as the third space of circulation. Mesotherapy is suggested to target the interstitial compartment that the substances administered via mesotherapy diffuse through interstitial compartment to the deep target tissues without being rapidly washed out by vessels [13].

The aim of hair mesotherapy is to restore the abnormal physiology causing alopecia by stimulating various biological responses via injecting the active substances into scalp. Additionally, mechanical stimulation by needling itself creates a biologic response that is expected to stimulate mesodermal changes [10, 15]. Hair mesotherapy offers the prevention of hair loss, activation of new hair growth, and the improvement in the quality of existing hair. By hair mesotherapy, local microcirculation is increased, which improves the environment of hair follicle for better growth. Additionally, nutritional supply is provided to the hair follicle and the excess of dihydrotestosterone (DHT) is suggested to be neutralized [16].

\subsection{Solutions and substances}

There is no standardized formulation used in hair mesotherapy and the various ingredients can be given depending on the indication. Generally, cocktails containing mixture of different ingredients used in hair mesotherapy and they can be applied in alternation depending on the clinical response. It is important to remember that there may be interactions between the injected substances that interfere with the efficacy. However, there is no definite protocol for the compounds and the concentrations [9-11, 15]. Commonly used substances in hair mesotherapy include minoxidil, finasteride, dutasteride, biotin, tretinoin, pantothenic acid, pyridoxine, procaine, dexpanthenol, azelaic acid, T3/T4, and other vitamins and minerals [9-12]. These compounds have different biologic effects. Especially, buflomedil, minoxidil, finasteride, dutasteride, biotin, vitamins, and organic silicium are proposed to stimulate new hair growth [10]. Many of these substances have vasodilator effect. The main effects of the commonly used substances in hair mesotherapy are as follows:

Buflomedil is an $\alpha-2$ receptor antagonist and a weak calcium channel blocker. It has vasodilatory effect $[10,17]$. Minoxidil also has vasodilatory effect. It is the only drug that is proven to increase hair growth by prolonging the anagen phase [10,11]. Some authors do not use minoxidil more than $1 / 2 \mathrm{cc}$ in the cocktail since it may be painful for the patient [10]. Procaine is a well known anesthetic that provides patient comfort. It has vasodilator activity and enhances the absorption of other drugs [10,11]. Ginkgo biloba increases perifollicular blood flow. It also has antiedema and antioxidant effect. It contains diterpene which inhibits platelet activating factor and decreases platelet aggregation [10, 11]. Conjoctyl (organic silicium, salicylate of monometilsilanotriol) has an antioxidant and vasodilatory effect [10]. Dexpanthenol (Vitamin B5) is involved in the hair development. It is converted 
into pantothenic acid which is a precursor for the synthesis of coenzyme A, important in the carbohydrate metabolism [10,11]. Biotin acts as a coenzyme and growth factor. It has a role in the carboxylation and fatty acid metabolism [10,11]. Vitamin C acts as an antioxidant and helps in collagen production [18]. Vitamin A (retinoic acid) has a regulatory role in the growth of epidermal cells and keratinization process. It induces dermal fibroblastic activity and collagen production [18]. Pyridoxine (Vitamin B6) stimulates hair growth and augments the effects of zinc [11]. Cobalt, copper, lithium, magnesium, manganese, phosphorus, selenium, sulphur, and zinc can be used as trace elements [10]. Zinc acts as a 5- $\alpha$ reductase inhibitor [11]. Recently intradermal injection of copper has been suggested to be beneficial in AGA most likely by balancing the steroid-converting enzyme activity, enhancing the anagen phase of hair cycle, simultaneous transition to the telogen phase, and stimulation of the proliferation of dermal papilla cells [19]. Finasteride is an inhibitor of 5- $\alpha$ reductase enzyme and selectively interfere with the androgen activity on skin [18]. Dutasteride is a second generation 5- $\alpha$ reductase inhibitor. While finasteride inhibits type II enzyme, dutasteride inhibits both type I and type II [18]. Heparin and heparin-like mesoglycan acts as vasodilator [11]. X adene contains vitamin B complex and increases blood flow [11]. Azelaic acid inhibits 5- $\alpha$ reductase activity [11]. Calcitonin and cyproterone acetate can also be used in hair mesotherapy [10].

A test trichogram should be performed one year after to evaluate the clinical efficacy of hair mesotherapy. Additionally, mesotherapy injection technique has been suggested to decrease the pain and provide the distribution of drug more evenly during intralesional corticosteroid therapy for AA [20]. Shulaia et al. have reported successful results in AA patients treated with mesotherapy using nicotinic acid, vitamin $\mathrm{C}$, pentoxifylline, and trace elements $(\mathrm{Zn}, \mathrm{Se}$, and placentex) over a period of 28 weeks [21].

\subsection{Contraindications and side effects}

The contraindications of hair mesotherapy are as follows: allergy to the substances used in mesotherapy, diabetes, liver, renal and cardiac failure, pregnancy, lactation, use of medication for anticoagulation, infection, or lesion on the area [11, 22]. Side effects of hair mesotherapy are edema, bruising, itching, pain, and headache [10, 23]. Also, side effects related to the systemic absorption of substances may be observed [11]. Contrarily, alopecia has been reported as a side effect following hair mesotherapy. In one case report, one patient developed cicatricial alopecia after heparinoid vasodilator mesoglycan and reversible alopecia has occurred in the second patient due to homoeopathic agents [24]. Additionally, cutaneous infections caused by nontuberculous mycobacteria have been observed after mesotherapy. Although these infections are mostly reported after mesotherapy for lipolysis, physicians should keep in mind that they can be seen after hair mesotherapy [11, 25-27]. Moreover, multifocal scalp abscesses with subcutaneous fat necrosis and scarring alopecia have been reported as a complication of hair mesotherapy. This complication has been attributed to the improper application technique [28]. Recently, frontal edema due to $\% 5$ minoxidil solution after hair mesotherapy has been reported [29]. 


\subsection{Evidence for efficacy}

Unfortunately, there is scanty scientific data on the role of mesotherapy in the treatment of alopecia. Abdallah et al. have found hair mesotherapy more effective than placebo in 28 male AGA patients by using a dutasteride containing solution (dutasteride $5 \mathrm{mg}$, D-panthenol $500 \mathrm{mg}$, biotin $20 \mathrm{mg}$, and pyridoxine $200 \mathrm{mg}$ ) after 11 weeks of treatment. They also observed a negative correlation between the duration of AGA and response to treatment which is suggested to be associated with the replacement of terminal hair follicles with epithelial remnants of telogen follicles [30]. In another study, 90 male AGA patients were divided into three groups as group A (30 patients) receiving pure dutasteride, group $\mathrm{B}$ (30 patients) receiving dutasteride containing solution (dutasteride $5 \mathrm{mg}$, dexpanthenol $500 \mathrm{mg}$, biotin $20 \mathrm{mg}$, and pyridoxine $200 \mathrm{mg}$ ), and group C (30 patients) receiving saline. According to the results, there was no statistically significant difference between groups, however, dutasteride containing solution was found to be superior according to trichogram results [31]. Ozdoğan et al. have treated 15 male and 8 female AGA patients with mesotherapy using $2 \%$ minoxidil, biotin, dexpanthenol, herbal complex, and procaine once a week. Hair mesotherapy was found to be significantly effective in the improvement of hair quantity and hair thickness after 10 weeks [32]. A mesotherapy solution containing dutasteride $0.5 \mathrm{mg}$, biotin $20 \mathrm{mg}$, pyridoxin $200 \mathrm{mg}$, and D-panthenol $500 \mathrm{mg}$ was used in 86 female AGA patients and the results were compared with control group receiving saline solution. A decrease in hair loss and improvement in both photographic assessment and hair density after 12 sessions were observed [23]. Topical application of minoxidil 2\% (30 patients) was compared with the intraepidermal injection of the drug (30 patients) on 60 females with FPHL and it was concluded that the mesotherapeutic application of minoxidil revealed significantly better results compared to topical application of the drug in both self assessment and trichogram tests [33]. Freund et al. have treated 40 male AGA patients with mesotherapy using botulinum toxin. They have applied two injections at 24-week intervals after a 12 weeks period without treatment. After 48 weeks of first injection, statistically significant increase in mean hair counts was observed. They suggested that botulinum toxin relaxes the scalp muscles and reduces the pressure on the perforating vessels resulting in the increase of blood flow and oxygen concentration. Furthermore, they reported that there is an increased oxygenation of the scalp so the hair follicles may be associated with enhanced conversion of testosterone to estradiol which favors high oxygen concentrations [34].

Recently, in a systematic review, two unpublished trials (NCT01655108, EUCTR2013-002740-85ES) have been reported on the efficacy of mesotherapy for the treatment of FPHL. First trial (54 patients) has compared the application of minoxidil 0.5\% (27 patients) with saline $0.9 \%$ (27 patients) using mesotherapy technique. Although the study is ongoing, the results regarding the increase in hair volume and decrease in the extent of hair loss were better in minoxidil group. The second was a randomized, double-blind, and placebo-controlled clinical trial evaluating the efficacy of plasma rich in growth factors (PRGF-Endoret) on 24 male and female AGA patients by comparing with saline solution. The results of the study are awaiting publication [35]. 


\section{Microneedling in the treatment of alopecia}

\subsection{Introduction}

Microneedling is a medical procedure done by a drum-shaped roller device with hundreds of micron-sized microneedles (0.5-1.5 mm in length) projecting on it. Before the treatment, local anesthetics should be applied to the area.

\subsection{Method}

Roller device is applied in vertical, horizontal, and diagonal directions. By rolling the device across the skin, these microneedles pierce the stratum corneum and create numerous transient microchannels over the applied surface without damaging the epidermis [36, 37]. Microneedling provides direct entry to viable epidermis where it acts on, and does not contact with the dermal nerves and capillaries [37].

Generally, microneedling is applied at 4-6 week intervals in order to wait for new collagen synthesis. For acne scars, 3-4 treatment sessions may be required [36]. However, there is no standard protocol for the application of microneedling in alopecia treatment.

\subsection{Mechanism of action}

Microtrauma caused by puncturing of the skin induces the collagen synthesis and neo-angiogenesis through the wound healing response $[36,37]$. Microneedling leads the stimulation of stem cells and activation of growth factors [38-40]. It increases the blood flow to the hair follicles [40]. Also, it was reported that the expression of hair growth related genes are induced after microneedling [41]. Additionally, transient micropores formed through the procedure allow the delivery of molecules into the epidermis. Therefore, after microneedling many cosmeceutical agents have been suggested to be delivered deep to the skin [37, 42, 43]. Accordingly, in mesotherapy, substances can be given with mesoroller device, as mentioned above [11].

\subsection{Side effects}

Erythema is rapidly recovered in $24-48$ hours of treatment. No serious side effects have been associated with microneedling [37, 43]. Patients can complaint from mild pain [42]. As the microchannels close immediately after the application, infection is not expected after the procedure [36]. In order to avoid potential side effects, appropriate sterilization of the device and the use of only fully licensed and tested agents together with microneedling are important [37].

\subsection{Evidence for efficacy}

The effect of microneedling has been investigated on 100 men with AGA. Authors randomized the patients into two groups. First group (50 men) treated with weekly microneedling and $5 \%$ minoxidil twice daily (except the day of microneedling) and second group only treated with $5 \%$ minoxidil twice daily. After 12 weeks of treatment, the results regarding 
mean change in hair count were statistically better in the microneedling plus minoxidil group [38]. Additionally, the authors evaluated the supplementary effect of microneedling on four men with AGA who were on oral finasteride and topical 5\% minoxidil therapy. New hair growth was seen after 8-10 sessions. Patients treated weekly for the first four weeks, then 11 sessions were applied at 2-week intervals. After 6 months of treatment grade +2 to +3 response was seen in all patients on photographic assessment. Regarding the patient's subjective assessment scale three patients showed more than $75 \%$ satisfaction and one patient showed more than $50 \%$ satisfaction. After 18 months of follow up, the results of microneedling were reported to be sustained [44].

Lee et al. applied microneedling in conjunction with topical growth factors on eleven FPHL patients. In their scalp-split, single-blinded, and placebo-controlled trial, they treated patients weekly for five sessions. One half of the scalp was treated with a solution containing growth factors (basic fibroblast growth factor, insulin-like growth factor-1, vascular endothelial growth factor, stem cell factor, keratinocyte growth factor-2, superoxide dismutase-1, and Noggin) plus microneedling, whereas the other half was treated with saline plus microneedling. The increase in hair shaft density and hair count was significant in growth factor plus microneedling group. Also patients' satisfaction was reported to be higher in the same group compared to saline group [42].

Other than AGA, the effect of microneedling was also assessed in resistant AA. Deepak et al. reported three cases of AA (one patchy AA, two alopecia universalis) that were previously unsuccessfully treated with contact sensitizers, topical tacrolimus, minoxidil, and corticosteroids and oral mini pulse betamethasone. Authors applied microneedling with a solution containing triamcinolone acetonide, mesotherapy cocktail (growth factors, copper tripeptide-1, multivitamins, amino acids, and minerals), and minoxidil $2-5 \%$. Marked clinical response was seen in all the three of cases after 4-6 sessions. The authors suggested that scalp roller therapy might be an effective and safe complementary intervention for the treatment of resistant AA [43].

In another study, two cases of patchy AA were successfully treated with microneedling plus topical triamcinolone. After three sessions which were applied at 3-week intervals, both patients showed marked response and no recurrence was seen after 3 months follow up [40].

The role of photodynamic therapy (PDT) with methyl 5-aminolevulinic acid (MAL) has been studied for the treatment of AA with variable results. The lack of response has been attributed to the inadequate transepidermal penetration of the drug. With regard to facilitator effect of microneedling in drug delivery, the efficacy of roller therapy in the penetration of MAL in PDT of AA has been evaluated in two studies. Patients are treated with PDT with MAL with only half scalp application of microneedling. In both study, as none of the patients showed hair growth, authors concluded that PDT with MAL may not be an effective strategy for AA, regardless of adjunctive microneedling to enhance the drug passage deep into the skin $[45,46]$.

Recently, an animal study has demonstrated that micro injury caused by microneedling induced hair regrowth in two pomeranian dogs with alopecia $X$ (hair cycle arrest) [47]. In another animal study assessing the hair growth effect of mycophenolic acid (MP), microneedling was found to accelerate the stimulatory growth of topical MP on anagen follicles [48]. 


\section{Platelet-rich plasma in the treatment of alopecia}

\subsection{Platelets}

Platelets are one of the shapely structured elements of the peripheral blood and do not have cell nuclei. The number of platelets ranges from 150,000 to $350,000 / \mathrm{mm}^{3}$ in peripheral blood and they are functioning primarily in hemostasis [49]. They take active role in wound healing, angiogenesis, and inflammation owing to the numerous proteins, cytokines, and bioactive factors they contain $[49,50]$. In addition, they induce the migration and adherence of bone marrow-origin cells into angiogenesis territory and the differentiation of endothelial cell progenitors to the mature endothelial cells [51].

The platelets have three main storage sites; $\alpha$ granules, dense granules, and lysosomes [52]. The major growth factors (GF) and cytokines already stored in $\alpha$ granules are; transforming growth factor- $\beta$ (TGF- $\beta$ ), platelet-derived growth factor (PDGF), insulin-like growth factor (IGF-I, IGF-II), fibroblast growth factor (FGF), epidermal growth factor (EGF), vascular endothelial growth factor (VEGF), and endothelial cell growth factor (ECGF) [49, 53, 54]. The activation of platelets induces degranulation of GFs which are already restored. The secreted GFs bind to the transmembrane receptors on mesenchymal stem cells, osteoblasts, fibroblasts, endothelial cells, and epidermal cells and then induce the internal signal transduction pathway. They initiate the healing process such as cell proliferation, differentiation, chemotaxis, angiogenesis, matrix formation, osteoid production, and collagen synthesis [49, 53].

The dense granules of the platelets have bioactive factors such as serotonin, histamine, dopamine, calcium, adenosine triphosphate (ATP), adenosine diphosphate (ADP), and catecholamine. These substances have significant effects in wound healing. They have effects such as boosting the capillary permeability, vasoconstriction, hauling and activating the macrophages, tissue modulation, and regeneration [49, 54].

\subsection{Platelet-rich plasma}

PRP is an autologous, biologically active concentration, composed of many growth factors (GF), cytokines, and plasma proteins [55]. It came into use since 1970s owing to its effects to promote the wound healing to a cellular level [54]. Platelet concentration in PRP is at least $1,000,000 / \mu \mathrm{g} / \mathrm{L}$ in $5 \mathrm{~mL}$ and the growth factor concentration is 3-5 times higher than peripheral blood [49]. Platelet gel concentration which is higher or lower than 1,500,000 was associated with decreased angiogenic features of endothelial cells [56].

There are four different PRP subgroups available; pure PRP, leukocyte and PRP (L-PRP), platelet-rich fibrin matrix (PRFM), and leukocyte- and platelet-rich fibrin matrix. Clinically, pure PRP and L-PRP are widely used. The one widely used in cosmetic dermatology is the pure PRP [57].

In vitro studies indicate a dose-dependent positive correlation between the platelet concentration and human mesenchymal stem cells and fibroblast proliferation and type 1 collagen production [58]. It is reported that PRP increased the proliferation of fibroblasts and their transformation into myofibroblasts as well as the synthesis of collagen and matrix remodeling proteins $[59,60]$. 


\subsection{Preparation of platelet-rich plasma}

PRP is prepared with $20-60 \mathrm{~mL}$ of plasma [61] by means of automatic devices under aseptic conditions at $20-22^{\circ} \mathrm{C}$. It must be prepared using anticoagulants containing citrate dextrose solution formula A (ACD-A) or sodium citrate in order to inhibit PRP aggregation [53]. The blood elements are separated according to their molecular weights by means of centrifugal method in manual double spin method. Respectively, red blood cells (RBC) are the heaviest, white blood cells (WBC) are moderate, and the platelets are the lightest ones. The platelets are first separated from RBC and WBC by means of light-spin centrifuge that they become available in concentrated form in the top part of buffy coat layer. Subsequently, heavy-spin centrifuge separates the supernatant plasma and more concentrated platelets are obtained. Bottom part of the tube holds the platelets and the upper part retains the platelet-poor plasma (PPP). Thrombin is used as an activator to obtain coagulation and thus "activated PRP" is extracted by means of GF degranulation $[49,53]$. Approximately, 70\% of GFs is released in $10 \mathrm{~min}$ and almost $100 \%$ is released in an hour and a small amount of GF continues to be produced for up to 8-10 days during the life of platelets [62]. For this reason, PRP should be administered soon after it is prepared.

The platelet-rich fibrin matrix (PRFM) is developed to retard GF secretion from the platelets, which is a dense fibrin matrix generated by adding $\mathrm{CaCl}_{2}$ during the secondary centrifuge that induces the conversion of autogenous thrombin from prothrombin. Platelet activation decreases as the thrombin amount reduces, so the platelets secrete their GFs slowly in a period of 7 days. Therefore, it is used in fat grafting and soft tissue augmentation. At the same time, fibrin matrix serves as a building block in wound healing [49, 57].

L-PRP is a subtype of PRP consisting of the platelet, leucocyte, and red blood cells. It is produced by the collection of PPP and all buffy coats following the centrifuge of anticoagulant blood. Whereas Leukocyte-PRFM is a subform made up of platelet and leucocyte-rich fibrin polymerized clot. It is produced without using anticoagulant and activator [57].

Another platelet activation type is the method which stimulates PDGF and VEGF secretion and enables collagen-PRP gel formation, performed by using type I collagen [63].

A great number of commercial kits came into use in addition to manual PRP preparation. However, different technologies introduce products with different biology and unclear effect profile. There are various PRP preparation methods in the literature, which contain different protocols, different centrifugal techniques, and different cellular components [61].

\subsection{Indications}

Various indications of PRP in dermatology are outlined in Table 1 [53, 57, 64].

\subsection{Method}

The patients should be informed and a signed consent form should always be obtained prior to the application. The patient is required stop taking anticoagulants such as aspirin and 
Alopecia; androgenetic alopecia, and alopecia areata

Skin rejuvenation

Dermal volume augmentation

Scar revision; acne, and traumatic scars

Striae distensae

Chronic wounds

Fat grafting

Laser resurfacing

Lichen sclerosus

Table 1. Dermatological indications of PRP.

other nonsteroidal antiinflammatory medications at least 2 weeks before the application. Local anaesthesia should be given, if required, under aseptic circumstances. Different application methods are available, which may be preferred by the clinicians and for the comfort of the patient. First method is the retrograde injection of PRP deep-to-surface at a rate of $0.05-0.1 \mathrm{~mL} / \mathrm{cm}^{2}$ per each centimeter. The second one is the administration of PRP either by puncturing holes over the scalp by means of $1 \mathrm{~mm}$ microneedle roller or by means of mesotherapy gun. The third method is the application of PRP before or after the implantation in order to assist the hair transplantation, keeping the follicular grafts in PRP for 15 minutes prior to implantation or the application in order to speed up the wound healing in donor's excision line [53].

There is no consensus on the parameters such as the frequency, depth (interfollicular, intradermal, or subcutaneous), and the dose of the application.

\subsection{Contraindications}

Contraindications of PRP are listed on Table 2 [63-65].

Pregnancy and breastfeeding period

Acute and chronic infections

Autoimmune disorders

Sensitivity to blood and blood products

Hepatopathy (liver disease)

Malignancies

Thrombocytopenia and hypofibrinogenemia

Table 2. Contraindications of PRP. 


\subsection{Side effects}

The incidence of adverse effects is quite low since PRP application is an autologous one. Local side effects due to injection such as rash, ecchymosis, pain, and infection are mild and temporal. It does not have any risk of transmitting infections such as hepatitis B (HBV), hepatitis C $(\mathrm{HCV})$, and human immunodeficiency virus (HIV). Risk of allergy is low as the patient's own blood is used $[53,65]$.

\subsection{Evidence for efficacy of platelet-rich plasma in various conditions}

\subsubsection{Androgenetic alopecia}

AGA is characterized by progressive hair follicle miniaturization and its treatment is quite challenging [66, 67]. The two medications approved by Food and Drug Administration (FDA) are minoxidil and finasteride. Dermatologists and plastic surgeons tend to prefer new treatment methods due to limited effects and adverse effect profile of these agents. In recent years, a good number of studies have been carried out on the effectivity of PRP in an AGA treatment.

\subsubsection{The mechanism of platelet-rich plasma in androgenetic alopecia}

PRP enhances the proliferation of dermal papilla (DP) cells and protect the cells against apoptosis by increasing Bcl-2 protein level. Moreover, it stimulates the Akt signalization which has antiapoptotic effects on cell survival and also stimulates extracellular signal-regulated kinase (ERK) that regulates the cell growth. In this way, it promotes cell growth and extends the survival of hair follicles. B-catenin is expressed in the external root sheath in the bulge area of human anagen hair follicle and ensures the differentiation of stem cells into the hair follicle cells and other adult cells. B-catenin activity in DP cells of the patients treated with PRP is upregulated, inducing the differentiation of stem cells into hair follicle cells and stimulating the hair growth. In addition, FGF-7 expression in DP cells increases, ensuring that the anagen phase of hair growth cycle is extended. Enhanced VEGF and PDGF boosts the perifollicular vascular plexus with proangiogenic effect. Active PRP injected to the mice in vivo is indicated to induce the acceleration of telogen-to-anagen transition [68].

The first study performed on PRP indicated that both the survival of follicular units are increased and follicular density is augmented in the patients of hair plantation since the follicular grafts were soaked in PRP for 15 minutes prior to implantation [69]. Various studies in the literature indicated that PRP stimulates a number of active features such as growth rate, hair count, hair density, hair shaft diameter, hair root strength, anagen hair, telogen hair, terminal hair density, epidermal keratinocytes, hair follicular bulge cells, and lead to increase in small blood vessels in hair follicle, prevents dermal papilla apoptosis, extent anagen phase, and enhances hair regrowth [70-74]. The carrier which contains dalteparin/protamine micro particles (DP MP) (low-molecular-weight heparin) was used to enhance the efficiency of PRP. DP MP ensures adsorption, stabilization, and slow secretion of GFs. PRP containing DP MP is observed to increase the hair thickness significantly compared to PRP alone [75]. In another 
study, PRP containing $\mathrm{CD}^{+} 4^{+}$cell has been tried on patients with AGA and a significant increase has been observed in hair thickness [76].

\subsubsection{Alopecia areata}

AA targets the anagen hair follicles in which spontaneous remission may be observed [77-79]. Although immunosuppressive agents can generally be used in the treatment of AA and regarded as an organ specific autoimmune disease, there is not any curative or preventive treatment of the disease [80]. Therefore, PRP has been introduced in recent years as an alternative treatment.

\subsubsection{The mechanism of platelet-rich plasma on alopecia alopecia}

PRP has also an antiinflammatory effect in addition to its effect on the induction of proliferation. Endogen lipid molecules called "lipoxin" derived from cellular arachidonic acid serve in the resolution of the inflammation. Lipoxins retard the arrival of new neutrophils into the inflammation area and support the neutrophil apoptosis to organize the resolution. PRP promotes lipoxin A4 (LXA4) secretion and suppresses the cytokine secretions to limit the inflammation [81]. The fact that inflammatory cytokines play a part in the etiopathogenesis of AA led to an argument that PRP could be effective in AA treatment with antiinflammatory effect.

There is limited number of studies in the literature on the use of PRP in the treatment of AA. A recent study indicated a significant increase in hair growth, an increase in Ki-67 which is the cellular proliferation marker and a degradation in the rate of relapse, in AA patients treated with intralesional PRP, compared with the patients treated with both placebo and intralesional triamcinolone acetonide (TrA). Furthermore, it has been observed that both groups taking PRP and TrA had less rash and irritancy as well as reduced dystrophic hair in dermoscopy. A complete remission rate of $60 \%$ has been achieved in the group treated with PRP at the end of the treatment [79].

In another study carried out with 20 AA patients, PRP was well tolerated, no adverse effect was observed and improvement in hair growth was seen. Minimal response to treatment and relapse was observed in only one patient [82].

PRP treatment applied on an ophiasis-type alopecia areata patient, resistive to corticosteroid treatment, yielded a successful result and hair regrowth was observed. PRP is suggested to be an alternative treatment in AA patients resistive to corticosteroid treatment and in the patients with side effects of steroid injection [83].

\section{Laser and light sources in the treatment of alopecia}

Laser (light amplification by stimulated emission of radiation)/light sources have become popular in dermatology practice on various disorders. Recently, these devices have been tried for the treatment of male and female pattern hair loss and alopecia areata with variable success rates. The laser beam having the coherent, monochromatic, and polarized characteristics 
that differs it from the ordinary light. The low-energy laser light penetrates the surface in a defined position and does not damage the skin [84]. There is a consensus among many authors that current laser/light sources are safe methods if they can be used properly and also these treatment modalities can be used alone or in combination with other treatments. The literature reveals that the texture and quality of hair improves even if there is no hair regrowth by the use of laser/light sources [85].

\subsection{Androgenetic alopecia}

AGA is the most common form of hair loss that may affect up to $70 \%$ of men and $40 \%$ of women in their lifetime [86, 87]. The aim of the treatment is to stop miniaturization and induce hair thickening and regrowth [88]. Finasteride and minoxidil are the most common therapeutic drugs used for AGA [87]. But new treatment modalities are under investigation. Laser/light sources for AGA have become popular in the last few years.

Photobiomodulation is a term that is used to describe the effects of lower level light energy (650-900 nm) on the cellular level. The exact mechanism of photobiomodulation that stops or reduces hair loss in patients is not well known [85, 89]. Low-level visible light treatment (LLLT) modulates the gen expression of $5 \alpha$-reductase and vascular endothelial growth factor (VEGF) and consequently stimulates hair growth through androgen metabolism and angiogenesis [90]. It was previously reported that helium-neon (He-Ne) laser $(632.8 \mathrm{~nm})$ irradiation stimulates cellular activities like deoxyribonucleic acid (DNA) and protein synthesis, mitochondrial electron transport, and adenosine triphosphate (ATP) generation [91]. Low-level laser irradiation prolonged the duration of anagen phase and caused the catagen and telogen follicles to reenter into the anagen phase in a study in mice treated with He-Ne laser. It was revealed that He-Ne laser with a dose of $1 \mathrm{~J} / \mathrm{cm}^{2}$ shows stimulatory effects on hair growth with a significant increase in percentage of anagen, but a suppression of hair growth was observed at a dose of $5 \mathrm{~J} / \mathrm{cm}^{2}$. Cells with low growth rate or under stress conditions, give better response to low-level laser irradiation [90]. Low level of reactive oxygen species (ROS) occurred due to low doses of irradiation show stimulatory effects on cell metabolism, while high level of ROS due to high doses of irradiation show inhibitory effects [92-94].

Subsequently, paradoxical hypertrichosis was reported for many times after using laser and intense pulsed light (IPL) photoepilation therapy for hair removal [95-99]. It is not exactly known, how these light sources can induce hair growth. One possible mechanism is the activation of silent hair follicles or the synchronization of hair growth cycles by direct light stimulation [89]. Radmanesh et al. identified different mechanisms for developing hypertrichosis after the IPL. First, certain wavelengths of IPL show photostimulator effects on hair follicle germinative and stem cells, directly or indirectly and facilitate hair regeneration and growth. The stem cells in the bulge area of the hair follicle are usually inactive. The second mechanism is the stimulation of the secretion of the mediators and cytokines that stimulate hair growth by IPL. Keratinocyte growth factor and fibroblast growth factor are two well known trichostimulatory cytokines and they have stimulatory effects on hair follicles and epidermal cells. They maintain epidermal proliferation and hair growth. The individual differences and the properties of the devices may also affect the paradoxical hypertrichosis [98]. 
There are various studies showing the positive effects of laser/light treatments in AGA. In a previous study, the effects of laser on cancer were investigated in mice. The dorsal hair of mice was shaved and the low-powered ruby laser $(694 \mathrm{~nm})$ therapy was given toward this area. They did not find any evidence of cancer but observed accelerated hair growth in lasertreated sides [100]. In a clinical study, seven patients with a diagnosis of AGA were exposed to LLLT twice weekly for 20 min for 3-6 months. An increase in the number of terminal hair, a decrease in the number of vellus hair, and an increase in shaft diameter were observed in this study but these changes were not statistically significant [89].

To assess the effect of a $1550 \mathrm{~nm}$ fractional erbium-glass laser in a female pattern hair loss, 28 patients received 10 treatments at 2-week interval. At the end of the study, a marked increase in hair density and hair shaft thickness and significant improvement at the frontal hair recess were seen in patients. It was revealed that $1550 \mathrm{~nm}$ fractional erbium-glass laser may be a safe and effective treatment option for female pattern hair loss (FPHL) [101]. In a clinical study, the effects of a $1550 \mathrm{~nm}$ fractional erbium-glass laser on the hair cycle in an alopecia mouse model and on the treatment of male pattern hair loss were investigated. In the human pilot study, an increase in hair density and an improvement of growth rate were observed. In the animal study, the effect on hair stimulation was dependent upon the energy levels, densities, and irradiation intervals. Fractional laser irradiation can promote anagen hair growth and induce transition from the telogen phase to the anagen phase. It was shown that Wnt 5- $\alpha$ and $\beta$-catenin expressions play a role in hair growth were induced by laser irradiation [102].

In a study of 32 patients with male and female androgenetic alopecia, the efficacy and safety of LLLT were evaluated. A Laser comb $(655 \mathrm{~nm})$ was used as monotherapy or as a concomitant therapy with minoxidil and finasteride. Eight patients showed significant improvement, 20 patients showed moderate improvement while no improvement was observed in four patients. Improvement was observed in both monotherapy and the dual therapy group [103]. Previously, a Laser comb has been tested in 110 patients with AGA in a double-blind, sham device-controlled, multicenter, and 26-week trial. Significant increase in mean terminal hair density was observed in patients in the LLLT group when compared to patients in the sham device group [104]. Jimenez et al. reported a statistically significant increase in terminal hair density after 26 weeks of low-level laser comb device treatment compared with sham treatment in patients with FPHL and male pattern hair loss (MPHL) [105].

\subsection{Alopecia areata}

As there is no cure for alopecia areata which is an autoimmune disease and may improve spontaneously in $34-50 \%$ of patients, clinicians search for new treatment modalities such as laser/light sources [86, 106, 107].

There are limited studies about laser irradiation for alopecia areata. In a study, clinicians used $308 \mathrm{~nm}$ xenon chloride excimer laser $(\mathrm{XeCl})$ for two patients with alopecia areata for 11-12 sessions within a 9-11 weeks period. They observed homogeneous and thick hair growth. The exact mechanism was not clear, but immunosuppressive effects of laser irradiation by inducing T-cell apoptosis and interrupting autoaggressive immune cascade were 
held responsible [108]. In a study with nine patients with AA, 308-nm excimer laser was used for lesions twice a week for 12-24 sessions. They observed hair regrowth in patients with AA partialis [109].

In a previous study, researchers chose a single representative lesion that was unresponsive to the other treatments. One half of the lesion was exposed to the 308-nm laser while the other part was not treated. After 27 sessions, only the treated area showed hair regrowth, suggesting it was not a spontaneous recovery [110].

The 308-nm excimer laser was used for patients with AA twice a week for 24 sessions. And it is reported as an effective treatment for patchy AA of the scalp and in some cases with AA of the beard area, but patchy lesions of the extremities and alopecia totalis were unresponsive [111]. It was also used for children with patchy AA successfully. Atopic diathesis was considered as a poor prognostic factor in this study [112].

Waiz et al. used pulsed infrared diode $(904 \mathrm{~nm})$ laser on 16 patients with 34 resistant alopecia areata patches. They observed hair regrowth with a rate of $94 \%$. They suggest that laser may alter the cellular membrane or change the exposed antigen which was previously hidden to become hidden again [84].

Yoo et al. treated a patient with recalcitrant AA with fractional laser therapy weekly for 24 weeks. Hair regrowth was observed after 1 month treatment. After 3 months $30-40 \%$ of lesions were covered with terminal hair. Complete recovery occurred after 6 months of fractional laser therapy. One of the possible mechanisms of fractional laser induced hair regrowth is inducing T-cell apoptosis or decreasing inflammation. Another mechanism is about microscopic thermal columns in the dermis that were made by laser therapy. A healing process starts including lymphocyte infiltrations. It may scatter perifollicular lymphocyte infiltration and cause a decrease in perifollicular lymphocytic infiltration. Fractional laser may stop disease progression by increasing anagen phase. Furthermore, minor trauma and wound healing induced by fractional laser therapy may facilitate hair growth [113].

Three patients with ophiasis, a special pattern of AA, were enrolled in a study. Two of the patients were treated with nonablative $1550 \mathrm{~nm}$ erbium glass fractional laser (NAFL) and one of the patients treated with both NAFL and ablative 10,600 nm carbon dioxide fractional laser (AFL). The clinicians observed that patients who have AA for 1 year or less respond to treatment better than patients with long-term disease. They considered NAFL treatment may have beneficial effects on early ophiasis lesions [114].

\section{Stem-cell therapy in alopecia}

\subsection{Hair follicle, stem cells, and dermal papilla}

Hair follicle (HF) is a complex structure that contains important units in the development of hair shaft including dermal papilla, matrix, and bulge region [3]. 
The HF undergoes cycles of growth and degeneration that a new hair shaft is formed in each cycle [115]. The signaling in this cycling is not completely understood. Fundamentally, there is a bidirectional communication between the mesenchymal and stem cells within the hair follicle that controls the formation, growth, and cycling of hair follicle [3, 116, 117].

Dermal papilla (DP) is located at the bottom of hair follicle (hair bulb) and consists of specialized mesenchymal cells which produce signals regulating the hair cycling of follicular epithelium and also driving the formation of hair follicle [116, 117]. Bulge region of hair follicle houses epithelial stem cells that become progenitor cells forming the hair follicle. Upon the stimulatory signals from DP cells, progenitor cells move down to the deep dermis where they turn into matrix cells which differentiate to form different parts of hair follicle [3, 117, 118]. It can be understood from these information that although the immediate formation of hair shaft and follicle is achieved by the matrix cells in the DP, reservoir stem cells reside in the upward bulge region that maintain the follicle regeneration [115].

Stem cells are characterized by the capacity of self-renewal and ability to differentiate into various cell lineages. Hair follicle stem cells (HFSCs) which are found in hair bulge are quiescence cells that divide infrequently [3]. HFSCs are multipotent that they can give rise to all cells of a hair follicle, sebaceous gland, and interfollicular epidermis [3, 115, 118]. In addition, hair follicle bears other types of stem cells including interfollicular epidermal stem cells, sebaceous gland stem cells, follicle nestin + pluripotent stem cells, etc. [3, 115].

The induction of hair cycling and hair follicle regeneration from the HFSCs is a complex process which starts with the signals from DP cells. This interaction involves several signaling pathways, growth factors, specific protein ligand-receptor binding, upregulation of various hair-related genes and activation of different transcription factors [3, 116, 118].

\subsection{The rationale behind the stem-cell therapy in the treatment of alopecia}

As the current treatment options for most types of alopecia including AGA and AA are not satisfactory, new therapies are still being under investigation for various types of alopecia. Development of bioengineering technologies has provided the use of HFSCs as a promising treatment in the management of alopecia. Since the conventional drugs for alopecia are unable to target all the pathophysiologic factors, stem-cell therapy is considered as a potential solution to correct the main pathology in various types of alopecias [3, 115, 117, 118].

It has been suggested that the distinct pathophysiologic pathways may be targeted by stem cell therapies in different diseases. An important point is that in order to specifically manage the alopecia, it is important to clarify the exact etiologic mechanism underlying various types of alopecias [3, 118]. For example, in AGA, the main etiology is that the HF is miniaturized by the effect of 5-DHT and the signaling that drives the HF regeneration is impaired. Although the stem cells in bulge region are undamaged, the production of new hair formation is interrupted in AGA $[3,116]$. Another example for the impaired induction of hair formation by the destruction of DP region is the chemotherapy induced alopecia. Induction of hair generation by DP cells has been suggested to be achieved by stem-cell therapy in this type of alopecia [116]. In AA, DP (bulbar region of HF) is attacked by the immune cells [3, 115]. Stem-cell 
therapy has been suggested to be effective in the suppression of autoimmune destruction and recovery of immune balance in AA patients [119]. In cicatricial alopecia, inflammation leads to the destruction of the bulge region where the normal immune privilege has been lost by pathologic triggers and stem cells are destroyed [115]. Producing a new hair follicle unit via transplantation of stem cells has been suggested as a major innovation for the treatment of most forms of alopecias including scarring alopecia $[3,115,117,118]$.

\subsection{Preliminary hair follicle generation studies and obstacles in stem cell therapies}

As the epithelial-mesenchymal interaction is crucial in the development of HF, it is essential to coculture DP cells with stem cells in order to generate a complete HF in laboratory condition. However, it has to be in mind that it is not easy to obtain and grow stem cells in laboratory experiments and their turnover is low $[115,117]$.

Marazzi et al. have isolated human follicle DP and bulge cells and cultured them in human skin sample (organotypical culture). After injection of the cultured bulge and DP cells into deep dermis, epidermis forming ability of the cells was assessed. The authors suggested their methodology as a relevant source of bioengineered hair follicles for hair transplantation therapies in alopecia [120].

In a previous report, mouse embryonic skin-derived stem cells were used to form a hair germ and the resultant bioengineered follicle germ was intracutaneously transplanted to create a structurally correct hair follicle. On the back skin of a nude mouse, the transplanted follicle germ was able to form hair shaft, construct appropriate connection with surrounding tissue, and undergo cycling [121]. As the transplantation of a mature bioengineered hair follicle rather than follicle germ is considered to be more favorable in hair regeneration, Asakawa et al. in their animal study, have shown that ectopic transplantation of bioengineered hair follicles (created by follicle germ cells from embryonic pelage skin and regenerated in vitro culture) could develop a fully functional hair follicle in host. Authors reported that the results of the study have indicated transplantation of the bioengineered hair follicles could replace the conventional FUT therapy in alopecia treatment [122].

An important problem in the hair follicle regeneration studies is that cultured DP cells lose their inductive capacity after a few passages. Attempts including co-culturing with keratinocytes and adding growth factors to the medium have been done to effectively expand DP cells in vitro culture [117]. As the laboratory conditions and in vitro assays are far from the in vivo ambience of DP cells, to better simulate the real hair follicle, three-dimensional (3D) dermal spheric cultures have been generated [123]. To further increase the inductive capacity of DP cells and to enhance the reproducibility of assays, novel membranes for spheric culturing have been used [124]. One of the most important obstacles in hair regeneration studies is the results of animal or in vitro studies differ from those on human. Despite an intact HF can be formed in murine and embryonic cell experiments, incomplete HF are formed with human DPCs. Subcutaneous implantation of isolated human HFSCs and human scalp DPCs resulted in the formation of hair follicle-like structures in nude mice [125]. To overcome this problem strategies such as culturing DPCs with keratinocytes have been formulated [126]. Recently an acellular dermal matrix has been used to grow human epithelial and dermal cells from 
scalp tissue with promising results [127]. Recently, human DP cells from scalp tissue have been embedded into dermal-epidermal composites (DECs) and formation of complete HF has been observed [128].

By ongoing studies, it was realized that not only the close environment of HF but also the macro environment of HF is important in the growth induction of HF. As the adipocyte stem cells (ASCs) secrete growth factors and stimulate hair growth pathways and the activation of hair follicle stem cell by adipocyte lineage cells has been shown, ASCs and ASC-conditioned medium (ASC-CM) have been investigated in hair regeneration studies. DPCs which are cultured in ASC-CM showed increased proliferation. These studies suggested a role for ASCs in alopecia treatment $[117,129]$.

Bone marrow mesenchymal stem cells (BM-MSCs) have also been used to induce hair induction in vitro assays and tested for HF formation capacity in mouse models [116].

\subsection{Studies on the stem-cell therapy in alopecia}

In a randomized placebo-controlled trial, topical application of a commercially available solution containing HFSCs in male patients with AGA was found to be effective in the induction of hair growth and reduction of hair loss [130]. Supernatant of BM-MSC culture overexpressing Wnt1a has been shown to increase hair producing ability of DP cells. Additionally, intradermal injection of concentrated solution of the above mentioned supernatant enhanced the transition from telogen to anagen in mouse. Also, negative effect of a 5-DHT on hair related genes was restored with the addition of Wnt-CM. Study indicated a role for Wnt1a from MSCs in hair regeneration therapies for alopecia [116].

The effect of intradermal injection of commercially available ASC-CM product (containing hepatocyte growth factor, fibroblast growth factor-1, granulocyte colony-stimulating factor, granulocyte macrophage-colony-stimulating factor, interleukin-6, vascular endothelial growth factor, and transforming growth factor $\beta-3$ ) to 22 AGA patients (11 males, 11 females) has been studied. Patients were treated in six sessions at 3-5- week interval. Six male patients were also on finasteride treatment. Half-side comparison study has been undertaken in 10 patients. Hair counts were increased in all patients according to trichogram assays. In comparison study, hair count was increased in both side of the scalp, however, the increase was higher in the treatment side compared to the placebo side. The response in the placebo side is suggested to be related to the effect of injection itself or the diffusion of the solution to the other side [131].

In another study with the same product, 27 patients with FPHL were treated with the solution (ASC-CM) weekly with concurrent use of microneedling roller. Retrospective assessment of the results revealed significant increment in the hair density and thickness after 12 sessions [129].

An evidence to the alternative mechanisms of stem-cell therapy is the "stem cell educator therapy" which has been used for its immune modulation effect in nine AA patients. Cord blood stem cells (CB-SCs) have been used to be introduced to patient's blood in a closed loop 
system. Patient's lymphocytes are separated and cocultured with CB-SCs in vitro and returned to patient's circulation after "education." A significant suppression of CD8Tcell attacking and upregulation of the co inhibitory molecules resulted in the diminishment of autoimmune destruction and reversal of immune balance by shifting the immune response toward Th2. As only a small portion of lymphocytes encounter with CB-SCs, the educated immune response has been suggested to be expanded systemically leading a generalized outcome [119].

In a recent review, an unpublished study (NCT01286649) has been reported investigating the efficacy of injecting human autologous HF dermal sheath cup cells which have been taken by punch biopsy from the scalp of patients with AGA. The results of the study await publication [118].

\subsection{Contraindications and side effects of stem-cell therapy in alopecia treatment}

The presence of skin disease, inflammation or infection, having an allergic, autoimmune disease or cancer, pregnancy, and the usage of anticoagulant therapy are reported as contraindications of stem-cell therapy [131]. Most of the studies on stem-cell therapy in alopecia treatment reported no severe adverse effects [119, 129, 132]. Patients can feel pain when injection technique is used which can be overcome by nerve blockages, local anesthesia, cooling, or prescription of nonsteroidal antiinflammatory drugs [131].

\section{Conclusions}

Although the scientific data to support the validity of mesotherapy as a treatment option in alopecia is still lacking, there is an increasing interest in its use. Hair mesotherapy is not yet approved in the treatment of alopecia and the existing studies give variable results. Therefore, long-term studies on a large cohort of patients are necessary to document its efficacy and safety in alopecia treatment and to standardize the treatment protocols. Hair mesotherapy can be used as an alternative intervention in the treatment of AA, AGA, and telogen effluvium in patients without systemic diseases.

Despite the increasing interest in microneedling in the treatment of different types of alopecia, further randomized controlled trials are required to assess the efficacy of microneedling on alopecia.

Literature suggests PRP as an effective tool in AGA patients. PRP can be considered as an alternative treatment in AA patients not responsive to corticosteroid treatment or in the patients developing side effects due to steroid injections.

LLLT seems to be a safe and effective treatment option for patients with AGA, but more long-term placebo-controlled studies are needed to define the beneficial effects of laser/light sources for the management of this disease. The effects of laser/light sources are shown in many studies as mentioned above in AA. However, larger placebo-controlled studies should be performed to evaluate the beneficial and adverse effects of these devices. 
There is no conclusive data regarding the efficacy, applicability, and method of stem-cell therapy in the treatment of alopecia, however, it still remains as a potential intervention. Further studies are required with improved techniques to overcome challenges in regenerating intact HFs before clinical use. Also the cost and availability of such bioengineering therapies must be taken into consideration. Similar to the current follicular unit transplantation (FUT) therapy, in future, it is expected to transplant a complete HF created by stem cell technology and be able to treat various types of alopecia.

\section{Author details}

Selda Pelin Kartal ${ }^{1 *}$, Cemile Altunel ${ }^{2}$ and Bilgen Gencler ${ }^{1}$

*Address all correspondence to: pelin@dr.com

1 Ministry of Health Ankara Diskapi Yildirim Beyazit Education and Research Hospital Dermatology Clinic, Ankara, Turkey

2 Ankara Nato Hospital, Dermatology Clinic, Ankara, Turkey

\section{References}

[1] Qi J, Garza LA. An overview of alopecias. Cold Spring Harb Perspect Med. 2014;4(3). pii:a013615. DOI: 10.1101/cshperspect.a013615.

[2] Levy LL, Emer JJ. Female pattern alopecia: current perspectives. Int J Womens Health. 2013;5:541-56. DOI: 10.2147/IJWH.S49337.

[3] Santos Z, Avci P, Hamblin MR. Drug discovery for alopecia: gone today, hair tomorrow. Expert Opin Drug Discov. 2015;10:269-92. DOI: 10.1517/17460441.2015.1009892.

[4] Mysore V. Mesotherapy in management of hairloss - is it of any use? Int J Trichology. 2010;2:45-6. DOI: 10.4103/0974-7753.66914.

[5] Buz A, Görgülü T, Olgun A, Kargi E. Efficacy of glutathione mesotherapy inburns: an experimental study. Eur J Trauma Emerg Surg. 2015;42:775. DOI: 10.1007/s00068-0150607-8.

[6] Mammucari M, Maggiori E, Lazzari M, Natoli S. Should the general practitioner consider mesotherapy (intradermal therapy) to manage localized pain? Pain Ther. 2016;5:123-6. DOI: $10.1007 / s 40122-016-0052-3$.

[7] Chen DL, Cohen JL, Green JB. Injectable agents affecting subcutaneous fats. Semin Cutan Med Surg. 2015;34:134-7. DOI: 10.12788/j.sder.2015.0166.

[8] Prikhnenko S. Polycomponent mesotherapy formulations for the treatment of skin aging and improvement of skin quality. Clin Cosmet Investig Dermatol. 2015;8:151-7. DOI: 10.2147/CCID.S76721. 
[9] Konda D, Thappa DM. Mesotherapy: what is new? Indian J Dermatol Venereol Leprol. 2013;79:127-34. DOI: 10.4103/0378-6323.104689.

[10] Kutlubay Z, Karakus Ö. Hair mesotherapy. Hair Ther Transplant. 2012;2:1-3.

[11] Inanır I, Gençoğlan G. Hair mesotherapy. Turkiye Klinikleri J Cosm Dermatol-Special Topics. 2014;7:22-5.

[12] Nusbaum AG, Rose PT, Nusbaum BP. Nonsurgical therapy for hair loss. Facial Plast Surg Clin North Am. 2013;21:335-42. DOI: 10.1016/j.fsc.2013.04.003.

[13] Handog EB, Gabriel TG. Mesotherapy. In: Baran R, Maibach H, editors. Textbook of Cosmetic Dermatology. 4th ed. London: Informa Healthcare; 2010. pp. 411-12.

[14] Herreros FO, Moraes AM, Velho PE. Mesotherapy: a bibliographical review. An Bras Dermatol. 2011;86:96-101.

[15] Petit P. Mesotherapy and aging skin. Acta Dermatovenerol Croat. 2010;18:209-14.

[16] Dolar N. The mesotherapy of scalp. Turkiye Klinikleri J Cosm Dermatol-Special Topics. 2008;1:26-32.

[17] Gokdemir G. Has the effect of mesotherapy been proved? Turkderm. 2009;43:12-6.

[18] Gokdemir G. Mesotherapy and platelet-rich plasma for the treatment of hair loss. Turkderm. 2014;48:74-9.

[19] Skalnaya MG, Tkachev VP. Trace elements content and hormonal profiles in women with androgenetic alopecia. J Trace Elem Med Biol. 2011;25:50-3. DOI: 10.1016/j. jtemb.2010.10.006.

[20] Ferrando J, Moreno-Arias GA. Multi-injection plate for intralesional corticosteroid treatment of patchy alopecia areata. Dermatol Surg. 2000;26:690-1.

[21] Shulaia T, Kiladze N, Babilashvili I. Mesotherapy in treatment of alopecia areata. J Exp Clin Med. 2007;1:19-22.

[22] Bulam H, Ayhan S, Sezgin B, Özmen S, Çenetoğlu S. Mesotherapy: Is it the miracle at the edge of the needle or not? Turk Plast Surg. 2013;21:16-9.

[23] Moftah N, Moftah N, Abd-Elaziz G, Ahmed N, Hamed Y, Ghannam B, Ibrahim M. Mesotherapy using dutasteride-containing preparation in treatment of female pattern hair loss: photographic, morphometric and ultrustructural evaluation. J Eur Acad Dermatol Venereol. 2013;27:686-93. DOI: 10.1111/j.1468-3083.2012.04535.

[24] Duque-Estrada B, Vincenzi C, Misciali C, Tosti A. Alopecia secondary to mesotherapy. J Am Acad Dermatol. 2009;61:707-9. DOI: 10.1016/j.jaad.2008.11.896.

[25] Galmés-Truyols A, Giménez-Duran J, Bosch-Isabel C, Nicolau-Riutort A, Vanrell-Berga J, Portell-Arbona M, Seguí-Prat B, Gumá-Torá M, Martí-Alomar I, Rojo-Arias MÁ, Ruiz-Veramendi M. An outbreak of cutaneous infection due to Mycobacterium abscessus associated to mesotherapy. Enferm Infecc Microbiol Clin. 2011;29:510-4. DOI: 10.1016/j. eimc.2011.03.006. 
[26] Regnier S, Cambau E, Meningaud JP, Guihot A, Deforges L, Carbonne A, Bricaire F, Caumes E. Clinical management of rapidly growing mycobacterial cutaneous infections in patients after mesotherapy. Clin Infect Dis. 2009;49:1358-64. DOI: 10.1086/606050.

[27] Rivera-Olivero IA, Guevara A, Escalona A, Oliver M, Pérez-Alfonzo R, Piquero J, Zerpa $\mathrm{O}$, de Waard JH. Soft-tissue infections due to non-tuberculous mycobacteria following mesotherapy. What is the price of beauty. Enferm Infecc Microbiol Clin. 2006;24:302-6.

[28] Kadry R, Hamadah I, Al-Issa A, Field L, Alrabiah F. Multifocal scalp abscess with subcutaneous fat necrosis and scarring alopecia as a complication of scalp mesotherapy. J Drugs Dermatol. 2008;7:72-3.

[29] Gungor S, Kocaturk E, Topal IO. Frontal edema due to topical application of \%5 minoxidil solution following mesotherapy injections. Int J Trichology. 2015;7:86-7. DOI: 10.4103/0974-7753.160124.

[30] Abdallah M, El-Zawahry K, Besar H. Mesotherapy using dutasteride-containing solution in male pattern hair loss: a controlled pilot study. PALD. 2009;20:137-45.

[31] Sobhy N, Aly H, Shafee AE, Deeb MA. Evaluation of the effect of injection of dutasteride as mesotherapeutic tool in treatment of androgenetic alopecia in males. Our Dermatol Online. 2013;4:40-5.

[32] Ozdogan S, Erdal M, Oktar FD, Tan S. Hair mesotherapy in treatment of alopecia. J Clin Analytic Med. 2011;2:5-8.

[33] Azam MH, Morsi HM. Comparative study between 2\% minoxidil topical spray vs. intradermal injection (mesotherapy) for treatment of androgenetic alopecia in female patients: a controlled, 4-month randomized trial. EDOJ. 2010;6:1-12.

[34] Freund BJ, Schwartz M. Treatment of male pattern baldness with botulinum toxin: a pilot study. Plast Reconstr Surg. 2010;126:246-8.

[35] van Zuuren EJ, Fedorowicz Z, Schoones J. Interventions for female pattern hair loss. Cochrane Database Syst Rev. 2016;5:CD007628. DOI: 10.1002/14651858.

[36] Doddaballapur S. Microneedling with dermaroller. J Cutan Aesthet Surg. 2009;2:110-1. DOI: $10.4103 / 0974-2077.58529$.

[37] McCrudden MT, McAlister E, Courtenay AJ, González-Vázquez P, Singh TR, Donnelly RF. Microneedle applications in improving skin appearance. Exp Dermatol. 2015;24:5616. DOI: $10.1111 /$ exd.12723.

[38] Dhurat R, Sukesh M, Avhad G, Dandale A, Pal A, Pund P. A randomized evaluator blinded study of effect of microneedling in androgenetic alopecia: a pilot study. Int J Trichology. 2013;5:6-11. DOI: 10.4103/0974-7753.114700.

[39] Kim BJ, Lim YY, Kim HM, Lee YW, Won CH, Huh CH, Kang H. Hair follicle regeneration in mice after wounding by microneedle roller. Int J Trichology. 2012;4:117-30. 
[40] Chandrashekar B, Yepuri V, Mysore V.Alopecia areata-successful outcome with microneedling and triamcinolone acetonide. J Cutan Aesthet Surg. 2014;7:63-4. DOI: 10.4103/ 0974-2077.129989.

[41] Jeong K, Lee YJ, Kim JE, Park YM, Kim BJ, Kang H. Repeated microneedle stimulation induce the enhanced expression of hair-growth-related genes. Int J Trichology. 2012;4:117-30.

[42] Lee YB, Eun YS, Lee JH, Cheon MS, Park YG, Cho BK, Park HJ. Effects of topical application of growth factors followed by microneedle therapy in women with female pattern hair loss: a pilot study. J Dermatol. 2013;40:81-3. DOI: 10.1111/j.1346-8138.2012.01680.

[43] Deepak SH, Shwetha S. Scalp roller therapy in resistant alopecia areata. J Cutan Aesthet Surg. 2014;7:61-2. DOI: 10.4103/0974-2077.129988.

[44] Dhurat R, Mathapati S. Response to microneedling treatment in men with androgenetic alopecia who failed to respond to conventional therapy. Indian J Dermatol. 2015;60:2603. DOI: $10.4103 / 0019-5154.156361$.

[45] Yoo KH, Lee JW, Li K, Kim BJ, Kim MN. Photodynamic therapy with methyl 5-aminolevulinate acid might be ineffective in recalcitrant alopecia totalis regardless of using a microneedle roller to increase skin penetration. Dermatol Surg. 2010;36:618-22. DOI: 10.1111/j.1524-4725.2010.01515.

[46] Lee JW, Yoo KH, Kim BJ, Kim MN. Photodynamic therapy with methyl 5-aminolevulinate acid combined with microneedle treatment in patients with extensive alopecia areata. Clin Exp Dermatol. 2010;35:548-9. DOI: 10.1111/j.1365-2230.2009.03695.x.

[47] Stoll S, Dietlin C, Nett-Mettler CS. Microneedling as a successful treatment for alopecia X in two Pomeranian siblings. Vet Dermatol. 2015;26:387-90, e88. DOI: 10.1111/vde.12236.

[48] Jeong KH, Joo HJ, Kim JE, Park YM, Kang H. Effect of mycophenolic acid on proliferation of dermal papilla cells and induction of anagen hair follicles. Clin Exp Dermatol. 2015;40:894-902. DOI: 10.1111/ced.12650.

[49] Foster TE, Puskas BL, Mandelbaum BR, Gerhardt MB, Rodeo SA. Platelet-rich plasma: from basic science to clinical applications. Am J Sports Med. 2009;37:2259-72. DOI: $10.1177 / 0363546509349921$.

[50] Nachman RL, Rafii S. Platelets, petechiae, and preservation of the vascular wall. N Engl J Med. 2008;359:1261-70. DOI: 10.1056/NEJMra0800887.

[51] Jurk K, Kehrel BE. Platelets: physiology and biochemistry. Semin Thromb Hemost. 2005;31:381-92.

[52] Rendu F, Brohard-Bohn B. The platelet release reaction: granules' constituents, secretion and functions. Platelets. 2001;12:261-73.

[53] Arshdeep, Kumaran MS. Platelet-rich plasma in dermatology: boon or a bane? Indian J Dermatol Venereol Leprol. 2014;80:5-14. DOI: 10.4103/0378-6323.125467. 
[54] Sánchez-González DJ, Méndez-Bolaina E, Trejo-Bahena NI. Platelet-rich plasma peptides: key for regeneration. Int J Pept. 2012;2012:532519. DOI: 10.1155/2012/532519.

[55] Dohan Ehrenfest DM, Rasmusson L, Albrektsson T. Classification of platelet concentrates: from pure platelet-rich plasma (P-PRP) to leucocyte- and platelet-rich fibrin (LPRF). Trends Biotechnol. 2009;27:158-67.

[56] Giusti I, RughettiA, D'AscenzoS, MillimaggiD, PavanA, Dell'Orso L, Dolo V.Identification of an optimal concentration of platelet gel for promoting angiogenesis in human endothelial cells. Transfusion. 2009;49:771-78. DOI: 10.1111/j.1537-2995.2008.02033.x.

[57] Leo MS, Kumar AS, Kirit R, Konathan R, Sivamani RK. Systematic review of the use of platelet-rich plasma in aesthetic dermatology. J Cosmet Dermatol. 2015;14:315-23. DOI: 10.1111/jocd.12167.

[58] Liu Y, Kalén A, Risto O, Wahlström O. Fibroblast proliferation due to exposure to a platelet concentrate in vitro is $\mathrm{pH}$ dependent. Wound Repair Regen. 2002;10:336-40.

[59] Cho JW, Kim SA, Lee KS. Platelet-rich plasma induces increased expression of G1 cell cycle regulators, type I collagen, and matrix metalloproteinase-1 in human skin fibroblasts. Int J Mol Med. 2012;29:32-6. DOI: 10.3892/ijmm.2011.803.

[60] Kushida S, Kakudo N, Suzuki K, Kusumoto K. Effects of platelet-rich plasma on proliferation and myofibroblastic differentiation in human dermal fibroblasts. Ann Plast Surg. 2013;71:219-24. DOI: 10.1097/SAP.0b013e31823cd7a4.

[61] Dhurat R, Sukesh M. Principles and methods of preparation of platelet-rich plasma: a review and author's perspective. J Cutan Aesthet Surg. 2014;7:189-97. DOI: 10.4103/0974-2077.150734.

[62] Marx RE. Platelet-rich plasma (PRP): what is PRP and what is not PRP? Implant Dent. 2001;10:225-8.

[63] Fufa D, Shealy B, Jacobson M, Kevy S, Murray MM. Activation of platelet-rich plasma using soluble type I collagen. J Oral Maxillofac Surg. 2008;66:684-90. DOI: 10.1016/j. joms.2007.06.635.

[64] LynchMD,BashirS.Applications of platelet-rich plasmaindermatology:acriticalappraisal of the literature. J Dermatolog Treat. 2016;27:285-9. DOI: 10.3109/09546634.2015.1094178.

[65] Sarıcaoglu H, Gunay IT. Platelet rich plasma applications. Turkiye Klinikleri J Cosm Dermatol-Special Topics. 2012;5:34-7.

[66] Kaliyadan F, Nambiar A, Vijayaraghavan S. Androgenetic alopecia: an update. Indian J Dermatol Venereol Leprol. 2013;79:613-25. DOI: 10.4103/0378-6323.116730.

[67] Gupta AK, Carviel JL. Meta-analysis of efficacy of platelet-rich plasma therapy for androgenetic alopecia. J Dermatolog Treat. 2016;6:1-4.

[68] Li ZJ, Choi HI, Choi DK, Sohn KC, Im M, Seo YJ, Lee YH, Lee JH, Lee Y. Autologous platelet-rich plasma: a potential therapeutic tool for promoting hair growth. Dermatol Surg. 2012;38:1040-6. DOI: 10.1111/j.1524-4725.2012.02394. 
[69] Uebel CO, da Silva JB, Cantarelli D, Martins P. The role of platelet plasma growth factors in male pattern baldness surgery. Plast Reconstr Surg. 2006;118:1458-67.

[70] Alves R, Grimalt R. Randomized placebo-controlled, double-blind, half-head study to assess the efficacy of platelet-rich plasma on the treatment of androgenetic alopecia. Dermatol Surg. 2016;42:491-7. DOI: 10.1097/DSS.0000000000000665.

[71] Gentile P, Garcovich S, Bielli A, Scioli MG, Orlandi A, Cervelli V. The effect of plateletrich plasma in hair regrowth: a randomized placebo-controlled trial. Stem Cells Transl Med. 2015;4:1317-23. DOI: 10.5966/sctm.2015-0107.

[72] Singhal P, Agarwal S, Dhot PS, Sayal SK. Efficacy of platelet-rich plasma in treatment of androgenic alopecia. Asian J Transfus Sci. 2015;9:159-62. DOI: 10.4103/0973-6247.162713.

[73] Park KY, Kim HK, Kim BJ, Kim MN. Letter: Platelet-rich plasma for treating male pattern baldness. Dermatol Surg. 2012;38:2042-4. DOI: 10.1111/dsu.12037.

[74] Gkini MA, Kouskoukis AE, Tripsianis G, Rigopoulos D, Kouskoukis K. Study of platelet-rich plasma injections in the treatment of androgenetic alopecia through an one-year period. J Cutan Aesthet Surg. 2014;7:213-9. DOI: 10.4103/0974-2077.150743.

[75] Takikawa M, Nakamura S, Nakamura S, Ishirara M, Kishimoto S, Sasaki K, Yanagibayashi S, Azuma R, Yamamoto N, Kiyosawa T. Enhanced effect of platelet-rich plasma containing a new carrier on hair growth. Dermatol Surg. 2011;37:1721-9. DOI: 10.1111/j. 1524-4725.2011.02123.

[76] Kang JS, Zheng Z, Choi MJ, Lee SH, Kim DY, Cho SB. The effect of CD34+ cell-containing autologous platelet-rich plasma injection on pattern hair loss: a preliminary study. J Eur Acad Dermatol Venereol. 2014;28:72-9. DOI: 10.1111/jdv.12062.

[77] Hordinsky MK. Overview of alopecia areata. J Investig Dermatol Symp Proc. 2013;16:135. DOI: 10.1038/jidsymp.2013.4

[78] Gilhar A, Etzioni A, Paus R. Alopecia areata. N Engl J Med. 2012;366:1515-25. DOI: 10.1056/NEJMra1103442.

[79] Trink A, Sorbellini E, Bezzola P, Rodella L, Rezzani R, Ramot Y, Rinaldi F. A randomized, double-blind, placebo- and active-controlled, half-head study to evaluate the effects of platelet-rich plasma on alopecia areata. Br J Dermatol. 2013;169:690-4. DOI: 10.1111/bjd.12397.

[80] Alkhalifah A. Topical and intralesional therapies for alopecia areata. Dermatol Ther. 2011;24:355-63. DOI: 10.1111/j.1529-8019.2011.01419.

[81] El-Sharkawy H, Kantarci A, Deady J, Hasturk H, Liu H, Alshahat M, Van Dyke TE. Platelet-rich plasma: growth factors and pro- and anti-inflammatory properties. J Periodontol. 2007;78:661-9.

[82] Singh S. Role of platelet-rich plasma in chronic alopecia areata: our centre experience. Indian J Plast Surg. 2015;48:57-9. DOI: 10.4103/0970-0358.155271. 
[83] Donovan J. Successful treatment of corticosteroid-resistant ophiasis-type alopecia areata (AA) with platelet-rich plasma (PRP). JAAD Case Rep. 2015;1:305-7. DOI: 10.1016/j. jdcr.2015.07.004.

[84] Waiz M, Saleh AZ, Hayani R, Jubory SO. Use of the pulsed infrared diode laser (904 nm) in the treatment of alopecia areata. J Cosmet Laser Ther. 2006;8:27-30.

[85] Avram MR, Leonard RT Jr, Epstein ES, Williams JL, Bauman AJ. The current role of laser/light sources in the treatment of male and female pattern hair loss. J Cosmet Laser Ther. 2007;9:27-8.

[86] Iorizzo M, Tosti A. Treatments options for alopecia. Expert Opin Pharmacother. 2015;16: 2343-54. DOI: 10.1517/14656566.2015.1084501.

[87] McElwee KJ, Shapiro JS. Promising therapies for treating and/or preventing androgenic alopecia. Skin Therapy Lett. 2012;17:1-4.

[88] Tsuboi R, Itami S, Inui S, Ueki R, Katsuoka K, Kurata S, Kono T, Saito N, Manabe M, Yamazaki M, Guidelines Planning Committee for the management of androgenetic alopecia. Guidelines for the management of androgenetic alopecia (2010). J Dermatol. 2012;39:113-20. DOI: 10.1111/j.1346-8138.2011.01361.x.

[89] Avram MR, Rogers NE. The use of low-level light for hair growth: part I. J Cosmet Laser Ther. 2009;11:110-7. DOI: 10.1080/14764170902842531.

[90] Shukla S, Sahu K, Verma Y, Rao KD, Dube A, Gupta PK. Effect of helium-neon laser irradiation on hair follicle growth cycle of Swiss albino mice. Skin Pharmacol Physiol. 2010;23:79-85. DOI: 10.1159/000265678.

[91] Karu T. Primary and secondary mechanisms of action of visible to near-IR radiation on cells. J Photochem Photobiol B. 1999;49:1-17.

[92] Grossman N, Schneid N, Reuveni H, Halevy S, Lubart R. $780 \mathrm{~nm}$ low power diode laser irradiation stimulates proliferation of keratinocyte cultures: involvement of reactive oxygen species. Lasers Surg Med. 1998;22:212-8.

[93] Pal G, Dutta A, Mitra K, Grace MS, Romanczyk TB, Wu X, Chakrabarti K, Anders J, Gorman E, Waynant RW, Tata DB. Effect of low intensity laser interaction with human skin fibroblast cells using fiber-optic nano-probes. J Photochem Photobiol B. 2007;86:252-61.

[94] Kim YG, Pak SC, Lee SR. Hairless mouse epidermal antioxidants and lipid peroxidation assessed by He-Ne laser. Lasers Surg Med. 2000;27(5):420-6.

[95] Bouzari N, Firooz AR. Lasers may induce terminal hair growth. Dermatol Surg. 2006;32:460.

[96] Alajlan A, Shapiro J, Rivers JK, MacDonald N, Wiggin J, Lui H. Paradoxical hypertrichosis after laser epilation. J Am Acad Dermatol. 2005;53:85-8.

[97] Moreno-Arias GA, Castelo-Branco C, Ferrando J. Side-effects after IPL photodepilation. Dermatol Surg. 2002;28:1131-4. 
[98] Radmanesh M. Paradoxical hypertrichosis and terminal hair change after intense pulsed light hair removal therapy. J Dermatolog Treat. 2009;20:52-4. DOI: 10.1080/095466 30802178224.

[99] Bernstein EF. Hair growth induced by diode laser treatment. Dermatol Surg. 2005;31:584-6.

[100] Mester E, Szende B, Gärtner P. The effect of laser beams on the growth of hair in mice. Radiobiol Radiother. 1968;9:621-6.

[101] Lee GY, Lee SJ, Kim WS. The effect of a $1550 \mathrm{~nm}$ fractional erbium-glass laser in female pattern hair loss. J Eur Acad Dermatol Venereol. 2011;25:1450-4. DOI: 10.1111/j.1468-3083.2011.04183.

[102] Kim WS, Lee HI, Lee JW, Lim YY, Lee SJ, Kim BJ, Kim MN, Song KY, Park WS. Fractional photothermolysis laser treatment of male pattern hair loss. Dermatol Surg. 2011;37:4151. DOI: $10.1111 /$ j.1524-4725.2010.01833.

[103] Munck A, Gavazzoni MF, Trüeb RM. Use of low-level laser therapy as monotherapy or concomitant therapy for male and female androgenetic alopecia. Int J Trichology. 2014;6:45-9. DOI: 10.4103/0974-7753.138584.

[104] Leavitt M, Charles G, Heyman E, Michaels D. HairMax Laser Comb laser phototherapy device in the treatment of male androgenetic alopecia: a randomized, double-blind, sham device-controlled, multicentre trial. Clin Drug Investig. 2009;29:283-92. DOI: 10. 2165/00044011-200929050-00001.

[105] Jimenez JJ, Wikramanayake TC, Bergfeld W, Hordinsky M, Hickman JG, Hamblin MR, Schachner LA. Efficacy and safety of a low-level laser device in the treatment of male and female pattern hair loss: a multicenter, randomized, sham device-controlled, double-blind study. Am J Clin Dermatol. 2014;15:115-27. DOI: 10.1007/s40257-013-0060-6.

[106] Brzezińska-Wcisło L, Bergler-Czop B, Wcisło-Dziadecka D, Lis-Święty A. New aspects of the treatment of alopecia areata. Postepy Dermatol Alergol. 2014;31:262-5. DOI: 10.5114/pdia.2014.40923.

[107] Tosti A, Duque-Estrada B. Treatment strategies for alopecia. Expert Opin Pharmacother. 2009;10:1017-26. DOI: 10.1517/14656560902876368.

[108] Gundogan C, Greve B, Raulin C. Treatment of alopecia areata with the 308-nm xenon chloride excimer laser: case report of two successful treatments with the excimer laser. Lasers Surg Med. 2004;34:86-90.

[109] Zakaria W, Passeron T, Ostovari N, Lacour JP, Ortonne JP. 308-nm excimer laser therapy in alopecia areata. J Am Acad Dermatol. 2004;51:837-8.

[110] Raulin C, Gundogan C, Greve B, Gebert S. Excimer laser therapy of alopecia areata-side-by-side evaluation of a representative area. J Dtsch Dermatol Ges. 2005;3:524-6.

[111] Al-Mutairi N. 308-nm excimer laser for the treatment of alopecia areata. Dermatol Surg. 2007;33:1483-7. 
[112] Al-Mutairi N. 308-nm excimer laser for the treatment of alopecia areata in children. Pediatr Dermatol. 2009;26:547-50. DOI: 10.1111/j.1525-1470.2009.00980.x.

[113] Yoo KH, Kim MN, Kim BJ, Kim CW. Treatment of alopecia areata with fractional photothermolysis laser. Int J Dermatol. 2010;49:845-7. DOI: 10.1111/j.1365-4632.2009.04230.x.

[114] Cho S, Choi MJ, Zheng Z, Goo B, Kim DY, Cho SB. Clinical effects of non-ablative and ablative fractional lasers on various hair disorders: a case series of 17 patients. J Cosmet Laser Ther. 2013;15:74-9. DOI: 10.3109/14764172.2013.764436.

[115] Mokos ZB, Mosler EL. Advances in a rapidly emerging field of hair follicle stem cell research. Coll Antropol. 2014;38(1):373-8.

[116] Dong L, Hao H, Xia L, Liu J, Ti D, Tong C, Hou Q, Han Q, Zhao Y, Liu H, Fu X, Han W. Treatment of MSCs with Wnt1a-conditioned medium activates DP cells and promotes hair follicle regrowth. Sci Rep. 2014; 25;4:5432. DOI: 10.1038/srep05432.

[117] Zhang P, Kling RE, Ravuri SK, Kokai LE, Rubin JP, Chai JK, Marra KG. A review of adipocyte lineage cells and dermal papilla cells in hair follicle regeneration. J Tissue Eng. 2014; 27;5:2041731414556850. DOI: 10.1177/2041731414556850.

[118] Falto-Aizpurua L, Choudhary S, Tosti A. Emerging treatments in alopecia. Expert Opin Emerg Drugs. 2014;19(4):545-56. DOI: 10.1517/14728214.2014.974550. Epub 2014 Oct.

[119] Review. Erratum in: Expert Opin Emerg Drugs. 2015;20(2):347.

[120] Li Y, Yan B, Wang H, Li H, Li Q, Zhao D, Chen Y, Zhang Y, Li W, Zhang J, Wang S, Shen J, Li Y, Guindi E, Zhao Y. Hair regrowth in alopecia areata patients following Stem Cell Educator therapy. BMC Med. 2015; 20;13:87. DOI: 10.1186/s12916-015-0331-6.

[121] Marazzi M, Crovato F, Bucco M, Sironi MC, Tosca MC, Antonioli B, Chlapanidas T, Lucconi G, Rapisarda V, Scalise A, Vigo D, Faustini M, Torre ML. GMP-compliant culture of human hair follicle cells for encapsulation and transplantation. Cell Transplant. 2012;21(1):373-8. DOI: 10.3727/096368911X565010. Epub 2011 Mar 25.

[122] Toyoshima KE, Asakawa K, Ishibashi N, Toki H, Ogawa M, Hasegawa T, Irié T, Tachikawa T, Sato A, Takeda A, Tsuji T. Fully functional hair follicle regeneration through the rearrangement of stem cells and their niches. Nat Commun. 2012; 17;3:784. DOI: $10.1038 /$ ncomms1784.

[123] Asakawa K, Toyoshima KE, Ishibashi N, Tobe H, Iwadate A, Kanayama T, Hasegawa T, Nakao K, Toki H, Noguchi S, Ogawa M, Sato A, Tsuji T. Hair organ regeneration via the bioengineered hair follicular unit transplantation. Sci Rep. 2012;2:424. DOI: 10.1038/ srep00424. Epub 2012 May 28.

[124] Higgins CA, Richardson GD, Ferdinando D, Westgate GE, Jahoda CA. Modelling the hair follicle dermal papilla using spheroid cell cultures. Exp Dermatol. 2010;19(6):5468. DOI: 10.1111/j.1600-0625.2009.01007.x. 
[125] Balana ME, Charreau HE, Leirós GJ. Epidermal stem cells and skin tissue engineering in hair follicle regeneration. World J Stem Cells. 2015; 26;7(4):711-27. DOI: 10.4252/wjsc. v7.i4.711. Review.

[126] Tan T, Hu ZQ. Follicular cell implantation for induce hair follicle growth in nude mice. Nan Fang Yi Ke Da Xue Xue Bao. 2009;29(10):1987-9. Chinese.

[127] Qiao J, Zawadzka A, Philips E, Turetsky A, Batchelor S, Peacock J, Durrant S, Garlick D, Kemp P, Teumer J. Hair follicle neogenesis induced by cultured human scalp dermal papilla cells. Regen Med. 2009;4(5):667-76. DOI: 10.2217/rme.09.50.

[128] Leiros GJ, Kusinsky AG, Drago H, Bossi S, Sturla F, Castellanos ML, Stella IY, Balañá ME. Dermal papilla cells improve the wound healing process and generate hair budlike structures in grafted skin substitutes using hair follicle stem cells. Stem Cells Transl Med. 2014;3:1209-19 [PMID: 25161315 DOI: 10.5966/sctm.2013-0217]

[129] Thangapazham RL, Klover P, Wang JA, et al. Dissociated human dermal papilla cells induce hair follicle neogenesis in grafted dermal-epidermal composites. J Invest Dermatol. 2014;134:538-40.

[130] Shin H, Ryu HH, Kwon O, Park BS, Jo SJ. Clinical use of conditioned media of adipose tissue-derived stem cells in female pattern hair loss: a retrospective case series study. Int J Dermatol. 2015;54(6):730-5. DOI: 10.1111/ijd.12650.

[131] Buonocore D, Nobile V, Michelotti A, Marzatico F. Clinical efficacy of a cosmetic treatment by Crescina( $\left({ }^{\circledR}\right)$ human follicle stem cell on healthy males with androgenetic alopecia. Dermatol Ther (Heidelb). 2013; 20;3(1):53-62. DOI: 10.1007/s13555-013-0021-2. Print 2013 Jun. Erratum in: Dermatol Ther (Heidelb). 2013;3(1):113.

[132] Fukuoka H, Suga H. Hair regeneration treatment using adipose-derived stem cell conditioned medium: follow-up with trichograms. Eplasty. 2015; 26;15:e10. eCollection 2015. 
